\title{
HERANÇA DA RESISTÊNCIA DE MILHO A PRATYLENCHUS SPP. ( $\left.{ }^{(}\right)$
}

\author{
EDUARDO SAWAZAKI $(2,5)$, ANA INES LUCENA LORDELLO $\left({ }^{3}\right)$ \\ e RUBENS RODOLFO ALBUQUERQUE LORDELLO $(4,5)$
}

\begin{abstract}
RESUMO
As espécies de nematóides que mais causam problemas na cultura do milho no Brasil são Pratylenchus zeae e $P$. brachyurus. $O$ uso de variedades resistentes é o método ideal de controle, sendo que já foram identificadas fontes de resistência em alguns genótipos de milho. Utilizou-se a linhagem $\mathrm{Col} 2(22)$, considerada como resistente, e a lp 48-5-3, como suscetivel, mais as geraçōes F1, F2 e retrocruzamentos com o objetivo de obter informaçōes sobre a herança da resistência. Avaliaram-se esses genótipos em campo, em área infestada por P. zeae $(76 \%)$ e P. brachyurus $(24 \%)$, em Pindorama. Plantou-se o experimento em janeiro de 1986 e, após oitenta dias, coletaram-se amostras de ralzes dos tratamentos para avaliação do número de nematóides por grama de raiz. Os resultados mostraram que a diferença observada quanto à resistência entre as linhagens Col 2(22) e Ip 48-5-3 e, provavelmente, devida a dois pares de genes dominantes de efeitos genéticos aditivos. As herdabilidades no sentido amplo e restrito foram altas, respectivamente 82,0 e $80,8 \%$.
\end{abstract}

Termos de indexação: milho, herança, resistência, nematobides, Pratylenchus zeae, Pratylenchus brachyurus.

(1) Trabalho apresentado no XV Congresso Nacional de Milho e Sorgo, realizado em Belo Horizonte (MG), em 4-8 de agosto de 1986. Recebido para publicaçăo em 2 de julho de 1986.

(2) Seção de Mitho e Cereais Diversos, Instituto Agronómico (IAC), Caixa Postal 28, 13001 Campinas (SP).

$\left({ }^{3}\right)$ Laboratório de Nematologia, EMBRAPAIAC.

(4) Laboratório de Nematologia, IAC.

(5) Com bolsa de suplementaçăo do CNPq. 


\section{INTRODUÇÃO'}

Os nematóides de maior importância para a cultura do milho no Brasil, pela sua patogenicidade, distribuição e elevado número de indivíduos, são Pratylenchus zeae e $P$. brachyurus, como mostram os trabalhos de LORDELLO (1961, 1974), MONTEIRO (1963), LORDELLO et al. (1982, 1983 e 1985a) e BRANCALION \& LORDELLO (1982). Estudos de seu controle com nematicidas sistêmicos mostraram alta eficiência de alguns produtos, porém as dosagens empregadas nem sempre foram economicamente viáveis' (LORDELLO et al., 1982, 1983 e 1985a).

A existência de variabilidade genética em milho quanto à resistência a Pratylenchus spp. foi constatada por GEORGI et al. (1983) e LORDELLO et al. (1985b). Esses autores mostraram a viabilidade do uso de variedades resistentes como método de controle dessa praga, cujos danos são relevantes em algumas regiōes do Estado, principalmente nos plantios tardios (LORDELLO et al., 1985a).

Os trabalhos de LORDELLO et al. (1985a,b) identificaram os híbridos simples Hs 1228 [lp 48-5-3 x Col 2(22)] e Hs 1227 (Ip 48-5-3 x Ip 365-1), respectivamente, como resistente e suscetivel a Pratylenchus spp., o que permitiu concluir que a resistência era conferida pela linhagem Col 2(22). Com base nesses dados, utilizaram-se as linhagens $\mathrm{Col}$ 2(22) e ip 48-5-3 para estudo da herança da resistência a Pratylenchus spp., cujos resultados são apresentados.

\section{MATERIAL E MÉTODOS}

A linhagem de milho Col 2(22), originária de milho duro branco da Colómbia, à qual foi transferida a cor amarela (MIRANDA et al., 1978) e a lp 48-5-3, obtida da variedade de milho cateto Assis Brasil (MIRANDA et al., 1977), mais as respectivas geraçōes $F 1$, F2 e retrocruzamentos, foram plantadas em 9/1/86 em uma área infestada por Pratylenchus zeae e $P$. brachyurus, nas proporçбes de 74 e $26 \%$ respectivamente, na Estaçāo Experimental de Pindorama. Os tratamentos foram repetidos em dois blocos, sendo a parcela constituida de uma linha para as linhagens e geração $F 1$, e por duas linhas de $8 \mathrm{~m}$ para a geração F2 e retrocruzamentos. Utilizou-se o espaçamento de 1 metro entre linhas por 0,2 metro entre plantas. A linhagem ip 48-5-3 foi utilizada como controle, intercalada entre os demais tratamentos, com o objetivo de medir a variação da infestação dos nematóides entre as parcelas. No plantio, colocaram-se três sementes por cova para assegurar o estande. Posteriormente, o excesso de plantas foi desbastado, ficando uma planta por cova.

Efetuou-se a coleta de ralzes para avaliação do número de nematóides 80 dias após o plantio, amostrando-se dez plantas para as linhagens e geração $F 1$, cinqüenta plantas para a $F 2$ e retrocruzamentos e quatro para o controle em cada repetição. 
Para extração dos nernatóides, tomaram-se, sempre que possivel, $10 \mathrm{~g}$ de raizes, utilizando-se o processo do liquidificador associado às peneiras e ao Baermann modificado, como descrito por LORDELLO et al. (1982), acrescido das seguintes alteraçōes: (a) uso do liquidificador durante trinta segundos por amostra; (b) retirada do excesso de água das raizes, comprimindo-as entre duas espumas de plástico de $2 \mathrm{~cm}$ de espessura; (c) a suspensão obtida foi passada na peneira 100 e coletada na 325 e, em seguida, lavada com 1,5 litro d’água.

Devido às dificuldades do processo de avaliação do número de nematóides, avaliaram-se apenas cinqüenta plantas para a geração $F 2$ e retrocruzamentos e dezoito para a linhagem Ip 48-5-3; na linhagem Col 2(22) e geração $F 1$, avaliaram-se todas as parcelas.

Os resultados, em número de nematóides por grama de raiz, foram utilizados na forma original e transformados em logaritmo, para obtenção das médias e variâncias. Obtiveram-se as estimativas de herdabilidade no sentido amplo e no restrito com os dados transformados em logaritmo, respectivamente, segundo os métodos descritos por PETR \& FREY (1966) e WARNER (1952), e o grau de dominância, pela fórmula de PETR \& FREY (1966).

Os testes de escala e escala conjunta, relatados por MATHER \& JINKS (1971), foram utilizados para testar a adequação dos dados ao modelo aditivo dominante. O de escala conjunta serviu também para estimar os parâmetros genéticos de aditividade (â) e dominância (đ̂).

\section{RESULTADOS E DISCUSSÃO}

Os resultados das contagens de nematóides por grama de raiz encontram-se no quadro 1. A linhagem Col 2(22) e a geração $F 1$, comercialmente conhecida por IAC Hs 1228, apresentaram baixo número de Pratylenchus spp. nas raizes, o que mostra alta resistência desses genótipos, confirmando os resuttados de LORDELLO et al. $(1985 \mathrm{a}, \mathrm{b})$. O comportamento das geraçốes $\mathrm{F} 1 \mathrm{e}$ $\mathrm{RC}_{\mathrm{Col} \text { 2(22) }}$ igual ao pai resistente, indica que a resistência a Pratylenchus spp. é de dominância completa. A distribuição observada na geração F2 foi contínua, unimodal com assimetria negativa, apresentando plantas iguais aos pais e intermediárias. Considerando o total de plantas avaliadas e o número de suscetlveis (iguais à linhagem lp 48-5-3) na geração F2, pode-se concluir que no máximo dois pares de genes devem estar envolvidos na resistência a Pratylenchus spp.

Os resultados do teste de escala e de escala conjunta, no quadro 2, mostram que as médias dos genótipos, em número de nematóides por grama de raiz, ajustam-se ao modelo aditivo dominante, e que não há evidência de interação alélica entre os genes que condicionam a resistência. Os parâmetros gené ticos de aditividade (â) e dominância (â) obtidos no teste de escala conjunta fo- 
ram equivalentes em magnitude, indicando que os genes responsáveis pela resistência têm ação genética aditiva e dominância completa. $O$ grau de dominância foi de 0,93 , confirmando o resultado anterior.

Os valores obtidos para herdabilidade no sentido amplo e restrito foram altos, respectivamente 82,0 e $80,8 \%$, indicando que as diferenças observadas entre os genótipos são, em sua maior parte, de natureza genética. Esses resultados também mostraram que as variaçōes ambientes do campo, amostragem e do método de avaliação foram pequenas.

QUADRO 1. Média, variância, número de plantas e sua distribuição em classes de número de nematớides por grama de raiz, em populaçōes parentais e segregantes de mitho. Campinas, 1986

\begin{tabular}{|c|c|c|c|c|c|c|c|c|c|c|c|c|c|c|c|c|c|c|c|c|c|}
\hline \multirow{2}{*}{ Populaçōes } & \multicolumn{16}{|c|}{ Classes (1) } & \multirow{2}{*}{$N\left({ }^{2}\right)$} & \multicolumn{2}{|c|}{ Média $\left({ }^{3}\right)$} & \multicolumn{2}{|c|}{ Variância } \\
\hline & 1 & 2 & 3 & 4 & 5 & 6 & 7 & 8 & 9 & 10 & 11 & 12 & 13 & 14 & 15 & $>15$ & & $x$ & $\log x$ & $x$ & $\log x$ \\
\hline lp 48-5-3 & & & & & & & & & & 1 & 1 & 3 & - & 2 & 1 & 10 & 18 & 834 & 2,90 & 78670 & 0,0197 \\
\hline $\operatorname{Col} 2(22)$ & 10 & 8 & 2 & & & & & & & & & & & & & & 20 & 53 & 1,70 & 438 & 0,0252 \\
\hline$F_{1}$ & 4 & 10 & 4 & 2 & & & & & & & & & & & & & 20 & 83 & 1,86 & 1692 & 0,0481 \\
\hline $\mathrm{F} 2$ & 2 & 3 & 5 & 9 & 6 & 5 & 4 & 2 & 4 & 2 & 2 & - & 1 & - & 2 & 3 & 50 & 337 & 2,40 & 91297 & 0,1237 \\
\hline$R C_{1 p \text { 48-5-3 }}$ & & 1 & 2 & 5 & 7 & 6 & 5 & 1 & 5 & 2 & 2 & 3 & 2 & 1 & - & 8 & 50 & 444 & 2,60 & 82864 & 0,0746 \\
\hline $\mathrm{RC}_{\mathrm{Col} 2(22)}$ & 31 & 16 & 2 & 1 & & & & & & & & & & & & & 50 & 47. & 1,60 & 1050 & 0,0728 \\
\hline
\end{tabular}

(1) As classes relerem-se a intervalos progressivos de 50 nematठ̋ides por grama de raiz $(1=0-49,2=50-99, \ldots)$. (2) $^{2} \mathrm{~N}=$ nummero de plantas. ( ${ }^{3}$ ) Nematoides por grama de raiz

QUADRO 2. Valores de A, B e C do "teste de escala" e dos parâmetros média (â) e (đ̂) do "teste de escala conjunta" para o número de nematóides por grama de raiz
$A=-29 \pm 642$
$\hat{\mathrm{m}}=501,99 \pm 43,76$
$B=-42 \pm 80$
(â) $=458,66 \pm 43,94$
$C=295 \pm 1244$
(d) $=419,87 \pm 45,96$
$\chi^{2}(3 \mathrm{gl})=2,82 \mathrm{~ns}$ 
Considerando a hipotese de a resistência a Pratylenchus spp. ser condicionada por dois genes independentes, de ação genética aditiva e dominante, ter-se-ão três classes fenotípicas na geração F2 e retrocruzamentos com o pai suscetlvel. Denominando os genes de A e B, os genótipos A_B_ seriam resistentes, A_bb e aaB_, intermediários, e aabb, suscetiveis. As porcentagens teóricas de freqüência em cada classe são respectivamente de $56,25: 37,5: 6,25 \%$ para a geração F2, e de 25:50:25\% para o retrocruzamento. No quadro 3, encontram-se as freqüências esperadas e observadas em cada classe fenotípica, e o teste de $\chi^{2}$. $\mathrm{Na}$ geração F2, o teste de $\chi^{2}$ foi significativo, indicando que os desvios observados não são devidos ao acaso, enquanto no retrocruzamento, $0 \chi^{2}$ não foi significativo, mostrando ser aceitável a teoria de dois genes dominantes de ação aditiva. O desbaste do excesso de plantas é um dos fatores que pode ter contribuldo para os desvios significativos da freqüência de plantas observadas em F2.

A população das espécies de nematóides numa amostra geral dos tratamentos consistiu em $76 \%$ de $P$. zeae e $24 \%$ de $P$. brachyurus, próximas das porcentagens encontradas por LORDELLO et al. (1985a). Não foram determinadas as porcentagens dessas espécies nos genótipos contrastantes quanto à resistência, ficando a dúvida se a resistência observada na linhagem Col 2(22) atua contra uma ou ambas as espécies.

QUADRO 3. Resultado da análise da geração F2 e do retrocruzamento com o pai suscetivel considerando a hipótese de a resistência a Pratylenchus spp. ser condicionada por dois genes dominantes e de efeitos aditivos

Classes

fenotipicas

Freqūência

Observada Esperada $\chi^{2}$

Geraçäo F2

Resistente

19

28

2,89 ns

Intermediário

21

19

$0,21 \mathrm{~ns}$

Suscetivel

10

3

$16,33^{\star *}$

(3 gl)

$19,43^{* *}$

Retrocruzamento Ip 48-5-3

Resistente

Intermediário

Suscetível

8

12,5

1,62 ns

24

25

0,04 ns

18

12,5

2,42 ns

(3 gl)

$4,08 \mathrm{~ns}$

Obs.: Resistente abrange as classes 1 a 4; intermediário, 5 a 9, e suscettivel, as classes maiores que 10, conforme quadro $\%$. 


\section{CONCLUSÕES}

1) A resistência a Pratylenchus spp. observada na linhagem Col 2(22) é, provavelmente, devida a dois pares de genes dominantes de efeito aditivo.

2) As estimativas de herdabilidade no sentido amplo e no restrito foram altas, respectivamente de 82,0 e $80,8 \%$.

\section{SUMMARY}

INHERITANCE OF CORN RESISTANCE TO PRATYLENCHUS SPP.

The species Pratylenchus zeae and $P$. brachyurus are the most important nematodes in Brazilian com fields. Their control with systemic nematicides is efficient but frequently not economic. Previous work indicated that resistance to these nematodes could be found in some corn genotypes. The inheritance of com resistance to the nematodes was studied using lines of Col 2(22) (resistant) and Ip 48-5-3 (susceptible), the generations F1, F2 and backcrosses. The genotypes were sowed in a field infested with $P$. zeae $(76 \%)$ and $P$. brachyurus $(24 \%)$. The experiment was carried out at the Pindorama Experimental Station, State of Sāo Paulo, Brazil, in January of 1986. Eighty days after planting the number of nematodes per gram of roots was determined. The results indicated that the resistance to this pest for the line Col 2(22) was due to two dominant genes with additive effect. The heritability was high in broad and narrow sense being respectively $82.0 \%$ and $80.8 \%$.

Index terms: corn, inheritance, resistance, nematodes, Pratylenchus zeae, Pratylenchus brachyurus.

\section{REFERÊNCIAS BIBLIOGRÁFICAS}

BRANCALION, A.M. \& LORDELLO, L.G.E. Emprego de aldicarb e carbofuran no controle de nematóides em cultura de milho. In: REUNIAOO BRASILEIRA DE NEMATOLOGIA, 5., Londrina, 1981. Piracicaba, Sociedade Brasileira de Nematologia, 1982. p.197-202. (Publicação, 5)

GEORGI, L; FERRIS, J.M. \& FERRIS, V.R. Population development of Pratylenchus hexincisus in eight corn inbreds. Journal of Nematology, 15(2):243-252, 1983.

LORDELLO, A.I.L.; LORDELLO, R.R.A.; TREVISAN, W.L. \& SOLFERINI, O.B. Efeito do Carbofuran sobre uma população de Pratylenchus spp. em raiz de milho. In: REUNIÄO BRASILEIRA DE NEMATOLOGIA, 5., Londrina, 1981. Piracicaba, Sociedade Brasileira de Nematologia, 1982. p.35-39. (Publicação, 5)

vares de milho em área infestada por Pratylenchus spp. em duas épocas de plantio. Nematologia Brasileira, Piracicaba, 9:7, 1985a. (Resumo) 
LORDELLO, L.G.E. Milho atacado por nematóides. São Paulo Agrícola, São Paulo, 3(30): $6,1961$.

- Observaçōes sobre incidência de nematóides em uma cultura de milho. In: REUNIÄO DE NEMATOLOGIA, Piracicaba, 1974. Piracicaba, Sociedade Brasileira de Nematologia, 1974. p.33-36. (Publicação, 1)

LORDELLO, R.R.A.; LORDELLO, A.I.L.; SAWAZAKI, E. \& ALOISI SOBRINHO, J. Reação de genótipos de milho a Pratylenchus spp. em campo. Nematologia Brasileira, Piracicaba, 9:163-173, 1985b.

; SAWAZAKI, E.; LORDELLO, A.I.L. \& ALOISI SOBRINHO, J. Controle de Pratylenchus spp. em milho com nematicidas sistêmicos e com torta de mamona. In: REÚNIÃO BRASILEIRA DE NEMATOLOGIA, 7., Braslia, 1983. Piracicaba, Sociedade Brasileira de Nematologia, 1983. p.241-250. (Publicação, 7)

MATHER, K. \& JINKS, J.L. Biometrical genetics: the study of continuous variation. 2.ed. London, Chapman and Hall, 1971. 382p.

MIRANDA, L.T. de; MIRANDA, L.E.C. de; POMMER, C.V. \& SAWAZAKI, E. Methoramento do cultivar de milho IAC-1. Bragantia, Campinas, 37(8):63-70, 1978.

$\&$ - Oito ciclos de seleção entre e dentro de famnias de meios-irmãos no milho IAC-1. Bragantia, Campinas, 36(18):187-196, 1977.

MONTEIRO, A.R. Pratilencose do milho. Revista de Agricultura, Piracicaba, 38:177-187, 1963.

PETR, F.C. \& FREY, K.J. Genotypic correlations, dominance and heritability of quantitative characters in oats. Crop Science, 6:259-262, 1966.

WARNER, J.N. A method for estimating heritability. Agronomy Journal, 44:427-430, 1952. 